\title{
De janelas que perguntam: A retórica do visível na poesia de Daniel Jonas e Marcello Sorrentino
}

\author{
Célia Pedrosa \\ Universidade Federal Fluminense
}

\begin{abstract}
RESUMO: LEITURA COMPARATIVA DOS TEXTOS DO POETA BRASILEIRO MARCELLO SORRENTINO E DO PORTUGUÊS DANIEL JONAS, ANALISANDO O MODO COMO NELES UMA POÉTICA DO EXCESSO VERBAL E VISUAL PERFORMA O SENTIDO (SEMÂNTICO E SEMIÓTICO) E OS SENTIDOS (PERCEPTIVOS) COMO MOVIMENTO/FORÇA AO MESMO TEMPO INTENSOS E INCONCLUSOS, CONTRASTANDO COM CERTA DEMANDA DE REALISMO E COMUNICABILIDADE COM QUE SE TENTA LEGITIMAR A POESIA NA VIDA CULTURAL CONTEMPORÂNEA.
\end{abstract}

ABSTRACT: A COMPARATIVE READING OF THE BRAZILIAN POET MARCELLO SORRENTINO AND THE PORTUGUESE POET DANIEL JONAS, ANALIZING HOW IN THEIR WORK A POETICS OF VERBAL AND VISUAL EXCESS PERFORMS MEANING (SEMANTIC AND SEMIOTIC) AND THE SENSES (PERCEPTION) AS MOVEMENTS/FORCES THAT ARE BOTH INTENSE AND UNFINISHED, THUS CONTRASTING WITH THE DEMAND FOR REALISM AND COMMUNICABILITY THAT IS BEING USED TO LEGITIMIZE POETRY IN CONTEMPORARY LIFE.

PALAVRAS-CHAVE: POESIA E CULTURA CONTEMPORÂNEAS - VISÃO - EXCESSO KEY-WORDS: CONTEMPORARY POETRY AND CULTURE - VISION - EXCESS 
ara contextualizar nossa proposta de leitura comparativa, esboçando um campo poético comum a Portugal e ao Brasil, tomamos como referência o fato de que, tanto lá como aqui, importante linha de força parece ser hoje uma nova demanda de realismo. Como em outras manifestações dessa demanda ao longo da modernidade, a desauratização da linguagem do poema e da identidade do poeta é mais uma vez considerada condição de reaproximação da realidade cotidiana e, desse modo, de ampliação de seu alcance e recuperação da relevância cultural da poesia.

Em Portugal, isso é bem sinalizado por Rosa Maria Martelo, em ensaio publicado já em 2003, na revista Relâmpago, e intitulado justamente "Reencontrar o leitor: alguns lugares da poesia contemporânea". Remontando, de início, às origens da modernidade, ela ressalta que em Baudelaire a "somatização estrutural" de aspectos e ritmos da vida urbana não vai impedir um privilegiamento da palavra no qual começaria já a se tramar a tendência à abstração formal dominante no lirismo posterior. Face a essa tendência, que marcaria diferentes dicções da poesia portuguesa até fins dos anos 60, e sustentaria ainda hoje uma concepção canônica de qualidade literária, a ensaísta contrapõe a tentativa de renovação vinculada à "valorização de uma relação mais imediata, ou mais legível, com a experiência e, por conseqüência, capaz de uma maior cumplicidade com o leitor" (MARTELO,2004, p.240-243). Próxima à dicção mais subjetivista que vicejara nos anos 70, em torno do empenho crítico e poético de Joaquim Manuel Magalhães, essa tentativa é associada por ela à proposta defendida pelo poeta Manuel de Freitas no prefácio da antologia que organiza e sugestivamente intitula de Poetas sem qualidades (2002).

Quanto à poesia brasileira, alguns pontos de contacto podem ser traçados a partir da análise feita pelo crítico e também poeta Ítalo Moriconi, em 1998, de uma "volta do sublime" que na década de 90 retomaria a mesma tendência formalista e abstratizante cujo anti-lirismo remontaria à "desaparição elocutória do eu" de origem mallarmaica. No entanto, essa volta ao sublime, em princípio conservadora, vai mostrar, pela diversidade dos efeitos que obriga o crítico a ponderar, um caráter bem complexo. Pois Moriconi também vai nela valorizar o reinvestimento no verso longo e discursivo, isto é, numa poética da retórica e da eloqüência antagônica à excessiva rarefação própria a certa herança do poeta francês presente tanto em nossa poesia vanguardista, experimental, a partir dos anos 50, quanto no subjetivismo espontaneísta da 
poesia "marginal" que a ela visava se contrapor na década de 70 . Nesse reinvestimento, Ítalo enxerga uma forma de fazer a poesia participar de um momento de expansão e democratização do espaço e da fala públicos. E, embora reinvindique também que ela se torne mais coloquial e ligada à experiência cotidiana, convulsiva, da beleza e da vida, não deixa de reconhecer que uma linguagem mais formalmente elaborada, mesmo que até ao ponto do sublime, pode influenciar positivamente na formação de um leitor mais exigente, alimentado da releitura do cânone moderno, distinto daquele legitimado pelo elogio à ligeireza expressiva e comunicativa da contracultura e da cultura pop, como o suposto pela prática poética dos anos 70 (MORICONI, 1998).

Em Portugal, a contracultura e o pop não parecem ter afetado o estatuto da poesia e de suas relações com o leitor a ponto de justificar uma postura dúplice como a de Moriconi. Mas, até por isso mesmo, as considerações por este feitas sobre a situação brasileira podem fornecer subsídios também para a avaliação dos pressupostos da atual demanda portuguesa de desauratização e comunicabilidade. Pois a constatação de um constante e diversificado retorno dessa demanda, bem como das que se lhe contrapõem, em contextos e momentos distintos, ajuda a tornar mais claras suas ambigüidades e tensões. No que concerne à relação entre poesia e vida, esse retorno evidencia, paradoxalmente, a incontornável irresolução do real e dos realismos, bem como das estratégias de subjetivação que, figuradas em sua contínua busca, serviriam ainda à legitimação de diferentes concepções de escritura, de leitura e de relação entre ambas. E impõe assim também a necessidade de problematizar valores como os de aproximação, identificação e cumplicidade, de modo a que a função pública da poesia, assim como as noções mesmas de função e publicidade, possam ser repensadas sempre provocativamente.

A esse respeito, relembremos mais uma vez Baudelaire, que, se configura a relação entre a arte e a vida de seu tempo de modo agônico, na tensão entre experiência e memória, expressão e ficcionalização, somatização e formalização, o faz também através de seu endereçamento a um leitor reconhecido como simultaneamente íntimo e desconhecido, fraterno e hipócrita. Não por acaso, essa configuração é mobilizada predominantemente através de experiências do e com o olhar, através das quais o poeta retoma e desestabiliza o paradigma da visão clara, esclarecida e não mediada, fundamental à construção no Ocidente da idéia de representação da realidade. 
Essa marca da poesia e da prosa baudelaireanas, associada ao que aqui vamos chamar de retórica do visível, tem sido já bastante discutida. Mas não custa lembrar mais uma vez seu elogio ao pintor que, na condição mesmo de cronista de folhetins cotidianos, é considerado artífice de uma relação entre arte e vida cotidiana assentada no jogo entre visão e imaginação, entre o turbilhão diurno das ruas e a solidão noturna do quarto. Ou o valor ambíguo que em função desse mesmo jogo adquirem as janelas das casas ou as vitrines dos cafés parisienses, através das quais se encena uma experiência simultânea de aproximação e distanciamento, continuidade e descontinuidade, entre o eu e o outro, o dentro e o fora, o familiar e o estranho, o privado e o público. Experiência que, a propósito da história da pintura, Hubert Damish considera o valor básico e contraditório de toda janela, metáfora por excelência do quadro como lugar da visão enquanto referência e representação (1994, p.123-134).

Por esse caminho, fica patente a complexidade das relações entre poesia e vida comum (nas duas acepções desse termo, relativas ao corriqueiro e ao coletivo) nas estéticas mais ou menos realistas, mais ou menos figurativas ou abstratas, mais ou menos expressivas ou formalistas - categorizações que já em si mesmas, e em sua polarização, demandam um constante redimensionamento. Pois em todas se poderia ler e convidar a ler a poesia enquanto janela/ vitrine/quadro nos quais se manifestaria o visível do real, o real do visível, como efeito de uma convulsionada e "inevitável cisão do olhar". Esta seria o lugar e a condição mesmo de mobilização de uma subjetividade individual e/ ou coletiva sempre elidida, diferida, que ao olhar as coisas recebe delas simultaneamente um olhar inesperado, desestabilizante - como no emblemático poema baudelaireano em que a transparência da vitrine de um café parisiense expõe o sujeito lírico ao desconcertante enfrentamento de uma família de olhos mendigos. (BAUDELAIRE, 1990). Assim, como um quiasma em constante e precário deslocamento, a experiência de produção e recepção do olhar nas artes pictóricas das mais antigas às mais contemporâneas é compreendida por Georges Didi-Huberman, a partir da releitura da fenomenologia merleaupontyana e em estreito diálogo com a psicanálise tal como revista por Jacques Lacan ( DIDI-HUBERMAN, 1998).

Essas considerações orientam nossa proposta de leitura de dois poetas contemporâneos, Daniel Jonas, de Portugal, e Marcello Sorrentino, do Brasil - em cuja produção ressalta o investimento numa discursividade extensa, mesclando 
o excesso das imagens visuais ao da eloquência expressiva e argumentativa. Sob esse ângulo, ela se mostra bem antagônica ao tipo de demanda realista e comunicativa que lá como aqui vem tentando, como vimos se impor. Jonas, nascido em 1973, já publicou, desde 1997, quatro livros, incluindo o único que aqui analisamos, Os fantasmas inquilinos, de 2005. Marcello, nascido em 1975, teve seu primeiro e até agora único livro publicado em 2006, um pequeno sistema de incerteza. Neste, apesar disso, encontram-se mais explícita e intensamente elaboradas características que consideramos serem importantes também no livro do poeta português, e que por meio dessa comparação se tornam mais significativas.

Para introduzi-las, pode-se apontar de início o estreito vínculo entre a capa do livro de Sorrentino e um dos poemas de Jonas - através do qual já retomamos aqui nosso tema da retórica do visível. Na primeira, a inflexão filosóficoabstrata do título é já apresentada de forma instável, pelo contraste entre as idéias de sistema, incertez̧a e pequenez, reforçado, aliás, mais adiante também pela inusitada opção por não numerar as páginas do livro e apresentar no seu sumário uma ordenação que não corresponde à que realmente vai presidir a sequência de poemas.

Isso ocorre ainda pela associação do título a uma montagem de fotografia e desenho que confunde, como em produtos de computação gráfica, as categorias de realismo e artifício. E esse efeito é ativado mais uma vez na medida em que a montagem nos mostra uma figura masculina, ao mesmo tempo bem próxima, em primeiro plano, mas distante, porque de costas, e com o rosto sombreado, postada num banheiro, e ainda por cima duplicada frente a um espelho invisível. Aí parece então urinar e pensar, pensar enquanto urina, urinar enquanto pensa - simultaneidade rotineira, na verdade, mas tornada agora mais eloqüentes e provocativa por essa associação de recursos visuais e verbais.

Curiosamente, no livro de Jonas, o longo poema "Psicodrama" encena um movimento dúplice de confissão e reflexão associado ao do corpo que urina: "A diurese lembra-me de mim: mijo e perscruto no escroto quem sou/ (fecho o fecho, lavo-me nas mãos / a água fria, volto a sentar-me),/ as minhas costelas em Braille/ não são leitura para ninguém...” (p.97). Como indica o termo psicanalítico "psicodrama", encenar implica uma relação ao mesmo tempo próxima e distante, real e artificiosa, com uma subjetividade esboçada aí num espaço entre o olhar e o ser olhado, que fragmenta e convulsiona a realidade corporal, justo através da genitalidade que a ela poderia atribuir identidade, 
presença, função. Resulta disso uma trama irresolvida de corpo e pensamento, imediato da percepção e mediado da linguagem - todos aí expostos como materialidades ao mesmo tempo evidentes e arredias, uma face a outra, ambas face à vontade de leitura e compreensão.

Configuração semelhante vamos encontrar em outro também longo poema de Sorrentino, "Ensaio sobre mim mesmo", cujo título, por si só, como o de Jonas, já sugere a cisão, o espaçamento, como aspectos inextricáveis do processo de subjetivação. Ao longo do poema a precariedade e a incompletude desse ensaio vão se manifestando pelo modo como se articulam ou "entreolham" com inusitada lógica e igualmente inusitada expressividade, o narrativo e o reflexivo, o físico e o intelectual, o natural e o artificial, compondo, em torno mesmo do cronotopo identitário, originário e íntimo da casa, uma voz interrogativa, híbrida, tanto próxima quanto distante, contaminada de sua exterioridade: "Porque expulsei grafiteiros desta casa/ onde pichavam em todo canto:/ "Por que decorar um domicílio destinado à demolição?" / E agora estou no fundo, no meio, quase / a subi-la, escalando o fumeiro turbulento/ de seus antigos pensamentos./ E penso que não há senão beleza, enfim, na natureza/ e em todos os poetas que a tentaram coagir".

Nessa e em outras formas de psicodrama ou ensaio propostos por Jonas e Sorrentino, não se estabelece entre o verbal e o visual uma relação ilustrativa, representativa - antes se constituindo a aproximação deles como "apenas" um gesto ao mesmo tempo intenso e lacunar, aquém de toda estabilização semântica e de toda organicidade sintática. Pois ambos os poetas parecem tentar fazer de sua linguagem um protéico exercício por entre a convocação e a desestabilização de paradigmas e sintagmas, entre a vontade de forma e a forma como iminência nunca finalizada.

A começar pela explícita tematização da suspensão de limites entre o ver e o pensar, entre as formas e idéias próprias a cada um desses "domínios". Jonas, no poema que abre e dá título ao livro em tela, nos fala de sua "pulsão escopofílica/ pelo pensamento,/ observar o pensamento/ que se depõe exacto em vez do acto/ e repeti-lo tautológico depois e depois/ porque é breve a identidade da satisfação", para que se possa, ou não, "O problema do coágulo resolvê-lo/ no diâmetro de uma artéria comburente,/ bypass para aritmética afectiva,/ para outras inquirições melancólicas,/ o sabor de detroit, aquele diner/ agora desmantelado/ pela ocupação do karaokê/ ou as três 
objeções da república e depois a defesa na poética.” (p.13). Sorrentino, no poema "O cineasta, tentando respirar", nos diz deste que "abre uma grande clareira, quase como o escultor de coisas mortas,/ e depois sorri terrivelmente amando a idéia:/ Unindo o amor à idéia ao amor à matéria,/ como uma carta de amor que envia/ a si próprio..." , pois, como "explica" no poema "O escultor de idéias", "a vida é mesmo assim,/ espalhada sobre mim como uma mulher invisível/ esperando/ um arrebatamento ardente./ Porque as mulheres são como flechas/ tremendamente delicadas / que o homem inteiramente esquece/ entre outras idéias" .

Como se percebe nesses exemplos, a dicção auto-reflexiva dos poemas, típica da poesia moderna, ao mesmo tempo em que se instala vai sendo turbada pelo desdobramento do argumento em imagens visuais concretas, o mesmo ocorrendo, ao contrário e quiasmaticamente, no desdobramento da concretude de imagens visuais em argumentos abstratos. É o caso das mulheres/ flechas invisíveis esquecidas como outras idéias do escultor, ou do cineasta tentando respirar como um escultor de coisas mortas, nos versos de Sorrentino; ou o problema/coágulo sanguíneo em artérias com sabor de detroit misturado às objeções platônicas e aristotélicas, nos versos de Jonas.

Nessa figuração irresolvida, performante, entre o ver, o pensar e o dizer se esboça então uma semelhança pervertida, uma continuidade descontínua, reforçada ainda pela disparidade semântica que se estabelece no "interior" de cada um desses campos. Isso se dá através do modo como se entrecruzam, muitas vezes num mesmo poema, versos de inflexão mítica, religiosa, científica ou prosaica, conduzindo a sintaxe argumentativa e explicativa ao mais absoluto non-sense. Em Jonas, por exemplo, no poema "Cameo", lemos: "Não espero nenhum deus através duma máquina;/ sou eu, enfim, o afundador de diques, confundidor do/ entendimento,/ como uma grande maré quebrando ou/ como uma grande maré crescendo,/ e com luvas de pelica disponho o estojo de trepanação/ e no crânio de Munch penso a broca/ mas é o cérebro do mundo que quero fender./ São algumas árvores o arvoredo/ nesta práxis euclidiana modesta. Se bem/ que às vezes não me chegue bem/ tudo neste teatro de espectros, se é que não é nada/ mas - como dizer - por vezes sou guindado à penthouse do diabo/ mas não o entendo, não entendo a crise a Satã." (p.40).

Em Sorrentino, o poema "Vinha a natureza toda alterada com a questão Marcello" relata que "Vinha a natureza toda alterada com a questão Mar- 
cello:/1)fumando vaga-lumes, o vento vagava como um velho;/2)hibiscos viravam relógios de pólen nas tranças das heras;/3)era tão tarde que nenhum relógio tinha horas pra quão tarde era./ O problema não era Marcello. Marcello era a ponta do iceberg:/ entre sereias silentes, uma estátua sonhando que se ergue./ Que mata elefantes e vai às igrejas fazer-se marfim/ para dizer; Ó Deus, quero ser livre de Ti como Tu és de mim." E conclui: "Não. O problema de Marcello não era Marcello e sim/ pedir a Deus que lhe caísse o fogo todo da terra e o marfim; / ao Cristo, nos céus, carregando uma enorme cruz Louis Vuitton,/ passando fogos de artifício nos lábios como batom".

Esse efeito pode ser acompanhado ainda mais pontualmente no modo como nos dois poetas retornam constantemente imagens de um dado campo semântico, em especial o da natureza, outro traço marcante que os distingue face à poesia eminentemente urbana a partir da modernidade. Nos poemas acima referidos já se percebe como ela é referida, interagindo com uma autoreflexão angustiada e perdendo assim qualquer valor originário ou utópico, associada agora, por exemplo, a "práxis euclidiana", "teatro de espectros", "relógios de pólen", "sereias silentes" ou a batom e adereços "Louis Vuitton".

Mais uma vez a aproximação do diverso suspende a oposição, sem no entanto deixar de fugir também à mera identificação paradigmática. E a natureza passa a ser um cronotopo no qual ao mesmo tempo se convoca e suspende irresolvido o caráter analógico-metafórico característico de seu uso poético mais tradicional. Com ela se esboçam relações de descompasso e descontinuidade entre palavras e coisas, entre as próprias coisas - descompasso e descontinuidade que vão reger também as relações espaciais e temporais através das quais a subjetividade poética tenta se identificar e estabilizar. É o que podemos observar, por exemplo, nas imagens do mar que Sorrentino e Jonas constroem. O primeiro assim conclui o poema "Perversa aerostação": "Continua porém a natureza a fazer pessoas como eu,/ mandando-as de encontro ao céu, numa perversa aerostação./ Quem sabe o corpo enfim aprenderá sem perguntar?/ Mas de pernas de fora, tento ainda interrogar o mar,/ Enlouquecendo porque o mar não pára de responder,/ e vagas, e vagas são as respostas". Do mesmo modo, no já referido poema "Cameo", Jonas constrói a partir do mar uma relação quiasmática entre o ver e o ouvir/ser ouvido que torna vagas, irresolvidas as relações significativas que ele tradicionalmente sustentaria: "Não adianta discutir com os deuses, isso é ponto assente./ Se o 
mar murmura não é que Posídon ficasse de repente rabugento/ nem sibilinas as ervas marinhas. É tão só do tanto esperar,/ da solidez da solidão, por assim dizer,/ de ansiar generosa fatia da tua boca com verbos lá de dentro,/ isto para ser definitivamente mais claro. Mas não bem a tua boca/ que eu bem conheço,/ antes outra." (p.38).

Em ambos, como se vê, a concretude física da natureza, como a do corpo nu, com pernas que caminham ou bocas que comem e falam, é associada ao excesso discursivo, em vagas e murmúrios cuja intensidade e continuidade produzem paradoxalmente a dúvida, a expectativa irresolvida. Muitas e várias são as imagens que, dessa maneira, surpreendem pela inventividade provocativa, desrespeitosa, e vão transformando a natureza em referência fragmentária em meio a um fluxo caudaloso, no qual se performa uma experimentação caótica mas pertinazmente interrogativa de sensações, memórias e informações tanto reais quanto artificiosas, de toda ordem. Outro exemplo bastante expressivo pode ser visto nos versos em que os dois poetas fazem a brancura natural e pura da neve desatar uma rede de significações imprevistas, eufóricas e disfóricas,. Assim, associada ao efeito alucinógeno da anfetamina, no "Poema de amor anfetamínico", de Sorrentino, ela serve para compor o cenário noturno urbano de felicidade jovem no qual os amantes dançam e "é como se nevasse dentro da boate e os teus cabelos/ atraíssem todos os flocos e os fizessem negros/ (pois em tuas mechas navegam ainda os antigos petroleiros/ derramando o óleo denso dos porões nos teus cabelos)..."- um misto estranhamente onírico, e estranhamente comum, de brancura e negror, leveza e densidade, céus e porões, cabelos e petroleiros, beleza, natureza, amor, dança, tecnologia e destruição. Já em "I'm dreaming of a white Xmas", Jonas faz com que a neve se associe à mitologia natalina de modo a que nesta as renas acionem um provocativo jogo de semelhança fônica que se desdobra inesperadamente em glândulas supra-renais e, por essa via intrincada, conduzem a natural brancura a uma mistura de serotonina e opiáceas, remédio e veneno, alegria e desolação, mirra-presente de reis magos para um poeta rei magro, doente e alucinado: "doce endorfina/ das glândulas supra-renais/ alvas renas monta/ neste natal e mata-me/ o tempo que puderes/ para que eu esqueça/ e nada mais faça ou lembre a não ser/ esquecer. Ó doce neve vem, ó opiácea vem,/ veneno opimo de copioso rei/ dá-me-te, recebe-me/ que toco e o que toco/ transformo em ouropel/ ou mirra: sou um rei/ magro/ que vem e traz o que mirra...” (p.70). 
$\mathrm{O}$ mesmo procedimento que articula forças de analogia e continuidade às de dissemelhança e descontinuidade caracterizaria a poesia de John Ashbery, conforme aponta Viviana Bosi, revendo e adensando uma recepção que o vem tornando uma importante referência para a poesia e a crítica dessa virada de século (1999). Significativamente, é a ele, justamente, que o poeta e também crítico Paulo Henriques Britto vai associar Sorrentino, no texto que serve de Posfácio a seu livro. Em um e outro Paulo ressalta a construção sintática que, articulando desdobramento e fragmentação, logicidade e disparidade, organiza versos e estrofes em blocos ao mesmo tempo sólidos e frágeis. Essa via comparativa pode ser estimulada pela descoberta na poesia de Daniel Jonas, no poema "Nem um verbo nos move", de uma imagem que nomeia um importante poema de Ashbery, a do skater: “...Eu queria estar mais contente/ se soubesse haver razões para isso,/ depor-te a aporia destes dias/ e trabalhar com novas certezas./ Em vez disso skaters faíscam/ no centro da minha passagem, no meio/ da minha vida/ e a sua navegabilidade incondicional/ desliza nesta aspereza da retina." (p.15).

Aí, mais uma vez, na interação de confessional, argumentativo e percepção visual, patinadores inscrevem um movimento sem propósito, deslizando sobre a aporia de dias, espaços, corpos e palavras infensos à ancoragem dos sentidos e do sentido. Esse ludismo seria em princípio, segundo certa crítica, o único valor atribuível a uma inflexão dita neobarroca - assim identificada também em Ashbery - marcada por um gosto do excesso e do contrastivo. Nessa inflexão considerada também pós-moderna, se esterelizaria a linguagem poética como estilo, esteticista, ornamental, no qual se reduplicaria a trama espetaculosa, vazia da vida cultural contemporânea. Em Ashbery, no entanto, conforme mostra Viviana, assim como em Jonas, a imagem do skater aparece associada a uma situação de precariedade, incômodo e dor produzidos aqui pelo retorno atritante, quiasmático, a olhos assim tornados ásperos, da imagem de início por eles percebida em sua navegabilidade incondicional.

Tal navegação dolorida aparece também na poesia de Sorrentino. Diznos ele no poema "Aceno de novo, repito": "Encosto o queixo ao peito;/ penso dentro o som do sangue,/ e as gotas explodindo contra o solo/ na caligrafia da partida./ Julgo já não mais estar aqui./ Mas não parto, estou ancorado a todos os cantos:/ picam-me a veneno as ruínas de carícias/ e paralisado, a noite passa demoradíssima." Ou no "Poema de amor anfeta- 
mínico": " dois cat-lovers na correnteza da noite: já são duas./ acima os vampiros varam o vazio infinito das ruas./hoje somos marinheiros e uma boate é nosso ancoradouro,/ onde dançamos e somos deuses, como todos os outros." Esse movimento de leitura, empreendido através da intertextualidade com a poesia de Ashbery, remete ainda a um outro forte veio da modernidade - o do empenho e dos impasses da navegação poética de Rimbaud em seu "bateau ivre".

Sob esse viés, a poesia de Jonas e Sorrentino pode ser compreendida como tentativa de reativação de uma intensidade subjetivante semelhante àquela com que o poeta francês exercitou o ato poético para além da dicotomia entre a forma e o informe que segundo Martin Jay enrigeceu a produção e a crítica da poesia moderna (JAY, 2003). Essa intensidade pulsional sob vários aspectos se avizinha de uma força de feição surrealista, - e o transbordamento de imagens simultânea e descompassadamente afetivas, perceptivas e reflexivas encena uma constante e angustiada busca dos sentidos, do sentido, não desestimulada pelo contínuo adiamento ou suspensão de seu encontro. Não por acaso, o poeta surrealista português Alexandre O’Neill é um dos interlocutores nomeados dos poemas de Jonas. E, também significativamente, lembremos, é uma inflexão surrealista que Italo Moriconi, no ensaio já referido, considera um dos principais fatores de vitalidade do reinvestimento discursivo na nossa poesia da década de 90. Um e outro sugerem desse modo o interesse da reavaliação da produtividade dessa força ao longo da poesia brasileira e portuguesa do século XX e desse início do século XXI.

Em Jonas e Sorrentino ela se manifesta no uso emblemático da imagem da janela como motivação visual e verbal de uma pulsão escópica na qual interagem procedimentos de subjetivação, de experimentação da linguagem e de exploração de uma realidade tanto perceptiva quanto intelectiva, tanto corriqueira quanto estranhamente onírica. Diz Sorrentino no poema "A pergunta posta pela janela": "Bela é a minha janela/ que rasga o mundo em ângulos retos/ e por meios violentos contém o céu./ Um tudo-nada em único plano/ confluente na base de um homem./ Janela onde tudo passa, em corrente/ marinha, ou formando as fronteiras/ de objetos em guerra: envelheço. [...] Janela onde jamais um pássaro envelhece,/ que é retrato que também confunde/ o pássaro, janela-tangerina:/ eu nunca disse por que não sou aquela nuvem/ apesar dessa questão me interessar." 
Como se percebe, e lembrando as colocações de Georges Didi-Huberman, a poesia se confunde aí com um espaço por onde o que vemos nos olha e nos interroga sobre nossas próprias visão e consciência. Com ela a forma se oferece em formação, articulando geometria e violência, enquadramento e fluxo, reflexão e desejo, apresentando e transtornando a natural paisagem de céu, mar, pássaro e nuvem, num tecido tão intensamente visível e problemático quanto essa inusitada composição de janela e tangerina que o convoca mas só com ele se torna possível.

O mesmo ocorre no poema de Jonas que, à guisa de título, no sumário, apresenta o verso inicial, "Não o previra. Fizeram-se à pressa sinais": “.....ele empina o olhar,/ mas é como se os olhos/ quisessem descer e não pudessem. $\mathrm{O}$ contra-picado/ deixa-o pouco à vontade, mas de certa maneira sempre foi assim/ que os objetos o olharam. Mais acima, a coroá-lo/ como um halo insólito uma placa toponímica: estamos no centro./ Ele é o centro solitário./ Agora outra coisa. A cortina que dispensa a conveniente opacidade/ esconde a alma. A alma é de veludo./ Os ramos emaranham-se reflectidos na vidraça (ou são rugas do vidro?).......” (p.58) .Nesses versos percebe-se como uma sintaxe discursiva se desdobra na construção em princípio clara de uma perspectiva visual em que se confundem no entanto a placa toponímica e o halo insólito, a centralização e o distanciamento, do mesmo modo como se confundem o olhar e o ser olhado, o sujeito, o objeto e o dispositivo que os organizaria em perspectiva - ramos e rugas inscrevendo uma corrosiva e agônica força de temporalidade na transparência e na imediatez tornadas opacas de vidros, almas, palavras .

Essa poesia-janela performa então um empenho de acesso à realidade que, no entanto, não se conforma a padrões pré-determinados de realismo e comunicabilidade. Ao contrário, reafirma de modo insólito sua vontade de endereçamento e comunhão, nos impondo a pergunta sobre o sentido do ser comum e estar em comum, apostando numa força dos sentidos e de sentido que ao mesmo tempo aproxime e desafie o senso-comum. Pois incorporando em sua linguagem procedimentos e discursos característicos de seu tempo - o excesso visual e verbal, as mitologias da religião, da política, do conhecimento, do entretenimento, - ela o faz de modo a investi-los do valor que, segundo Jean-Luc Nancy é próprio de toda imagem, em que a atração nunca apaziguada do desejo se diferencia do aliciamento uniformizante do espetáculo (2003, p. 20). 
Desse modo, retoma e atualiza, desafiadoramente, como mostra o poema Shih, de Sorrentino, o pacto lírico, a vontade de fazer do poema canção, apelo, mão estendida: "Tenho um mapa na memória/ que no entanto muda de segundo a segundo,/ reescreve-se sozinho, nunca forma o nome de um país/, um oceano, uma cadeia montanhosa./ E como eu tremo no caminho dessa desordem./ Pois meus mortos não estão a salvo, e eu canto./ Estou voltando por um caminho truculento/ às coisas simples. Eu canto." Gesto que reverbera insistente também na poesia de Jonas: "Que nos resta senão linguagem para povoar o mundo?/ E no momento em que a linguagem defina o mundo/ esse mundo é recusado/ que não cabe à linguagem achar a definição/ nem ao objecto ser definível. A ausência/ embeleza o ausente/ e para o teu mel de lábio a incerteza do sabor de cada gota,/ um outro lábio que sofre/ essa incerteza. Um insistente fim, o estudo próximo,/ a reverberação da angústia;/ alguma coisa de importante foi esquecida./ Um poema é: nunca me deixes sozinho comigo./ Um poema é: não pode ser doutra maneira.” (p.82)

\section{Referência Bibliográfica}

BAUDELAIRE, Charles. O Spleen de Paris. Pequenos poemas em prosa. Lisboa: relógio d'água, 1990.

BOSI, Viviana. John Ashbery. Um módulo para o vento. São Paulo: EdUSP, 1999.

DAMISH, Hubert. "Les raisons du tableau" . In: . L'origine de la perspective. Paris: Flammarion, 1994.

DIDI-HUBERMAN, Georges. O que vemos, o que nos olha. São Paulo: Editora 34, 1998. FREITAS, Manuel de (org.). Poetas sem qualidades. Lisboa: Averno, 2002.

JAY, Martin. Campos de fuerza. "El modernismo y el abandono da forma". In:

Entre la historia intelectual y la crítica cultural. Buenos Aires: Paidós, 2003, p.273-291. JONAS, Daniel. Os fantasmas inquilinos. Lisboa: Cotovia, 2005.

MARTELO, Rosa Maria. Em parte incerta. Estudos de poesia portuguesa moderna e contemporânea. Porto: Campo das Letras, 2004.

MORICONI, Italo. A volta do sublime. In PEDROSA, Celia et alii. (org.). Poesia hoje. Niterói: EdUFF, 1998.

NANCY,Jean-Luc. Au fond des images. Paris: Galilée, 2003.

SORRENTINO, Marcello. Um pequeno sistema de incerteza. Rio de Janeiro: 7Letras, 2006. 